\title{
Classification and identification of inherited brachydactylies
}

\author{
NAOMI FITCH
}

From the Lady Davis Institute for Medical Research, Jewish General Hospital, Montreal, Quebec, Canada

SUMMARY A search for patterns of malformation in the brachydactylies has resulted in new ways te identify the different types. Type A-1 can be characterised by a proportionate reduction of the middle phalanges. Type $B$ is thought to be an amputation-like defect. In type $C$ the fourth middle phalan $\vec{P}$ is usually the longest, and type $\mathrm{E}$ (Riccardi and Holmes, 1974) is characterised by short metacarpal $\overrightarrow{\mathrm{E}}$ and short distal phalanges. Short stature is usually present in type A-1 and type E brachydactyl (Riccardi and Holmes, 1974) and it may be present in some individuals with brachydactyly C. As short children have short hands, it is possible that in patients with very mild expressions of brachydactyly the cause of the short stature may be overlooked. It is suggested that in every child with propori tionate short stature the hands should be carefully examined. If the hands are disproportionatel short, if any distal creases are missing, if there is a shortening, however mild, of any finger, if an广火火 metacarpals are short, then it is important to have $x$-rays to look for brachydactyly $\mathrm{A}-1, \mathrm{C}$, or $\mathrm{E}_{\mathrm{co}}^{-}$

Much information is still needed. It is important in future reports to have skeletal surveys, patterm profile analyses, and to note the height of children with brachydactyly C. Most interesting of all wilb be when fetal limbs of each type become available for study.

Brachydactyly was the first human anomaly to be recognised as an example of Mendelian inheritance. In 1951, Bell classified the inherited brachydactylies into 5 types. In type A-1 brachydactyly the shortening is confined mainly to the middle phalanges, which may be fused to the distal ones. Only the middle phalanx of the index finger is abnormal in type A-2, and in type A-3 only the middle phalanx of digit 5 is abnormal. In type $B$ the middle and terminal phalanges are short or absent. Type $C$ is characterised by a defect in the middle and proximal phalanges of digits 2 and 3 . Type $D$ consists of a short, broad distal phalanx in the thumb. In type $\mathrm{E}$ one or more of the metacarpals or metatarsals are short.

McKusick (1975) added type A-4, in which the middle phalanges of digits 2 and 5 were short and there was radial clinodactyly of finger 4 , and type A-5 in which the middle phalanges were missing.

Bell's classification, with the exception of type E, is a very useful one. However, a survey of published reports indicates that it is sometimes very difficult to know how to identify ${ }^{1}$ a given family, and that there are some pedigrees which have been incorrectly

\footnotetext{
${ }^{1}$ Identification is defined as the act of allocation of an object to the correct class.
}

Received for publication 8 June 1978 identified or never identified. The reason for this could be the result of the way Bell described the different types. Her description focused almos $\widehat{Q}$ exclusively on the most obvious abnormality, and as a result, her classification of pedigrees has many over laps. For example, her type $\mathrm{C}$ consists of 13 pedigrees: 6 of which are said also to be type E. Anothe problem with Bell's classification is type $\mathrm{E}$ which Bell herself stated was heterogeneous. However? there has been only one attempt (Hertzog, 1968) to subdivide this group.

One purpose of this paper is to present a morê comprehensive analysis of each type, in order t $\Theta$ improve identification. It is not always recognise that some types of brachydactyly are frequently. associated with short stature, and a second purpose् of this paper is to emphasise this point. The thira purpose of the paper is to subdivide type $\mathrm{E}$.

\section{Classification of brachydactyly}

The following list is arranged so that the mutation which affect only one or two bones are listed first (1 to 7), a more complex malformation is listed next (8), then the brachydactylies which are usually accompanied by short stature $(9,10)$, and finall type $\mathrm{C}$, which may be associated with short stature 
(11). Bell type $\mathrm{E}$ has been subdivided into a type in which only the second metacarpal is short (Holmes and Remensnyder, 1972), a type in which only the fourth metacarpal is short (Stiles, 1939), a type in which only the fourth metatarsal is short (Steggerda, 1942), and a type in which both the fourth metacarpals and the fourth metatarsals are affected (Boorstein, 1926). As there are very few descriptions of families with only one shortened metacarpal or metatarsal, it is possible that, in the future, types 5,6 , and 7 may be shown to be the result of the same gene.

Types A-4 and A-5 have been omitted for reasons which will be discussed later.

(1) Short broad distal phalanx of the thumb. (Bell type D.)

(2) Abnormal middle phalanx of digit 2. (Bell type A-2.)

(3) Abnormal middle phalanx of digit 5. (Bell type A-3.)

(4) Short metacarpal 2. (Bell type E.)

(5) Short metacarpal 4. (Bell type E.)

(6) Short metatarsal 4. (Bell type E.)

(7) Short metacarpal and metatarsal 4. (Bell type E.)

(8) Apical dystrophy. (Bell type B.)

(9) Farrabee type. (Bell type A-1.)

(10) Short stature, short metacarpals and distal phalanges. (Bell type E.)

(11) Brachymesophalangy 2, 3, and 5. (Bell type C.)

All are inherited as autosomal dominants with variable penetrance and wide expressivity.

\section{Pathogenesis}

The pathogenetic analysis in this paper follows the analysis of animal limb mutations as described by Grüneberg (1963). These have been classified as follows: (a) Defects in chondro-osseous transformation.

(b) Defects in cartilaginous skeleton.

(c) Defects observable in the foot plate before the onset of chondrification. Alterations in the size and shape of the foot plate distort the normal limb pattern and produce absence, reduction, altered shape, or increased number of bones. In this group 'the mesenchyme seems to be used according to the same rules as in normal development' (Grüneberg and Lee, 1973).

(d) Amputation-type defects, which consist of abrupt termination of digits.

In this paper it is postulated that brachydactyly $\mathrm{C}$ may be an example of a defect in chondro-osseous transformation, brachydactyly A-1 may be partially a defect in the size of the blastema, and brachydactyly B may be an amputation-type defect.

In normal development the hands and feet differentiate within the foot plate in a proximodistal sequence. The blastema, which are condensed from mesenchyme, chondrify and then ossify. The first phalangeal bones to ossify are the distal phalanges which sometimes, if not always, ossify by intramembranous ossification. The next bones to ossify are the proximal phalanges, and the last are the middle phalanges (O'Rahilly and Gardner, 1975).

\section{Identification of types $8,9,10$, and 11}

\section{APICAL DYSTROPHY. BELL TYPE B}

\section{Description}

In this type of brachydactyly the terminal portions of fingers 2 to 5 are absent (Fig. 1). Usually the nails are missing, a feature unique to this type of brachydactyly. Forty-one $x$-rays of type B were studied (Kidd, 1909; Clarke, 1915; Cragg and Drinkwater, 1917; MacArthur and McCullough, 1932; Wells and
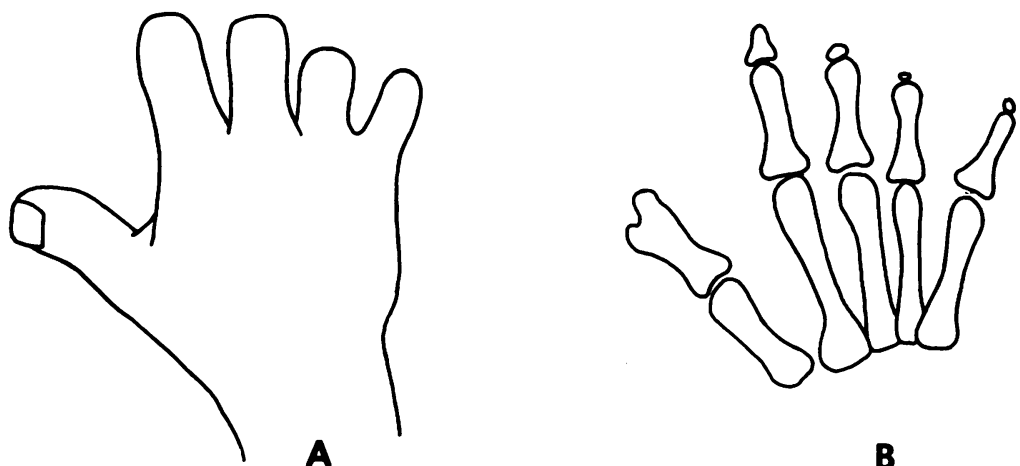

B
Fig. 1 Brachydactyly type $B$. 
Platt, 1947; Malloch, 1957; Bass, 1968; Temtamy and McKusick, 1969; Cuevas-Sosa and GarciaSegur, 1971; Battle et al., 1973; Goswami and Chaurasia, 1974; Zavala et al., 1975). In 17, the thumb was broad and sometimes bifid. The feet were similarly involved, but to a lesser extent. Digits 2 and 3 in the hand were often less severely affected than digits 4 and 5 . Syndactyly and symphalangism were sometimes present.

The proximal phalanges were of normal length. There may be no other bony elements in the digits, or a small spherical bone, or a bone which is often in the shape of a distal phalanx. The milder expressions of this gene (Temtamy and McKusick, 1969; Zavala et al., 1975) seem to be fusion of the middle and distal phalanges, or, in the case of the thumb, the proximal and distal phalanges. The proximal phalanges may have thin diaphyses, resulting in an hour-glass shape (Cragg and Drinkwater, 1917; Wells and Platt, 1947; Temtamy and McKusick, 1969; Battle et al., 1973). Temtamy and McKusick (1969) described one affected individual in whom the trapezium and trapezoid were fused in both wrists.

\section{Discussion}

The appearance of the fingers, on external examination and $x$-ray, is one of sudden termination, as if amputated. This is the only brachydactyly in which the nails, an ectodermal derivative, are affected. In an excellent paper on brachydactyly B, MacArthur and McCullough (1932) point out that a similar type of limb abnormality, myelencephalic blebs, is produced by a gene in the mouse (Bagg, 1929; Bean, 1929). Blebs are formed at the distal ends of the developing extremities. This results in amputation-like deformities, syndactyly, and a bifid or

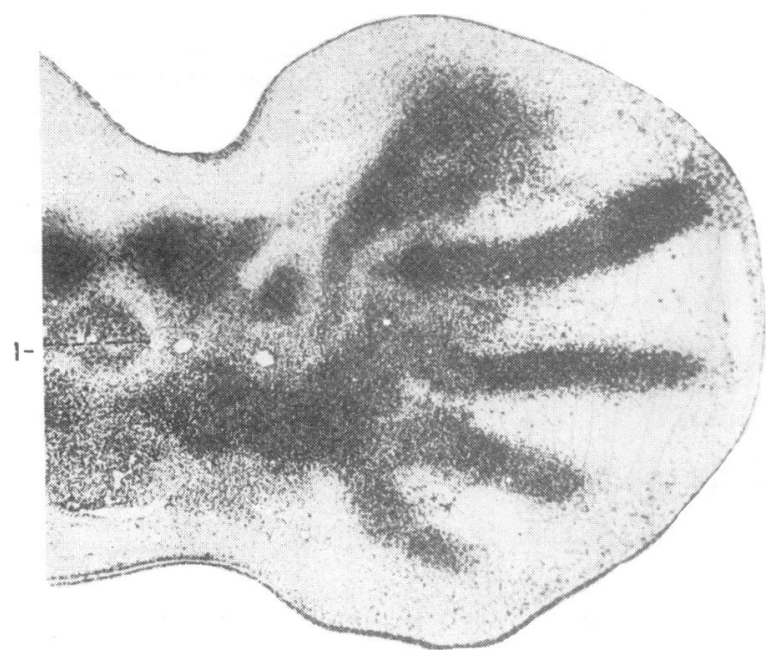

double first digit. Another animal model is brachydactyly in the rabbit (Greene and Saxton, 1939; Inman, 1941). The marginal limb vessels rupture early $\overrightarrow{\vec{s}}$ in fetal life, the tip of the limb becomes oedematous and haemorrhagic, and necrosis occurs. This results in limbs with shortened and missing bones, and $\overline{\bar{N}}$. absent or rudimentary nails. The shortened phalanges may assume the shape of a distal phalanx, or may be mere spicules.

MacArthur and McCullough (1932) postulate that $\vec{\circ}$ in type B brachydactyly a traumatic event occurs at: the apex of the hand and foot plate at the stage at which the digits begin to separate. Separation of the digits occurs at about the 15 to $25 \mathrm{~mm}$ stage (Fig. 2) In view of the increased width of the thumb in type $B$, it is interesting to note the relative width of thethumb blastema compared to the other digits. The tendency to polydactyly in the myelencephalic blebo mice (Carter, 1959) is confined to the preaxial side of the foot. It is interesting that this abnormality is not always accompanied by a bleb.

Most investigators call the terminal bones middle phalanges, though they often have the shape of dista phalanges. However, other investigators (Bass, 1968 ن Cuevas-Sosa and Garcia-Segur, 1971) call the terminal phalanx the distal one, and state that the middle ones are absent. This type has been calledo type A-5 (McKusick, 1975). However, as the $x$-rays are indistinguishable from type B, I agree witlo Herrmann (1974) that they should be included i⿳⺈, type B. Typical of this type are the bifid thumbs io Bass's family and the syndactyly in Cuevas-Sosa anf Garcia-Segur's family.

The problem of whether the terminal phalanges are middle or distal ones cannot be solved in the absence of studies on type B fetal limbs. However

Fig. 2 Normal human hand, $14 \mathrm{~mm}$ stage (From ' $\mathrm{Lim}$ ( Development and Deformity', by Swinyard, p.52,196\% Courtesy of Charles C. Thomas, Springfield, Illinois) $\overrightarrow{\mathbb{Q}}$ 
there are several facts which suggest that the terminal phalanges are really the middle ones which have assumed the shape of distal ones. Greene and Saxton (1939) noted that the terminal phalanges of brachydactylous rabbits look like distal ones. Similar shape changes can be found in the shortened bones of the myelencephalic bleb mice and in bones terminated in the human by amniotic constriction bands (Kino, 1975). Another indication that the terminal bones are middle phalanges is provided by Fig. 2 and 6 in Cuevas-Sosa and Garcia-Segur's paper (1971) and in Fig. 2 in Bass's paper (1968). Some of these phalanges do not have the shape of distals, but of middles which are short. MacArthur and McCullough (1932) were convinced that the terminal phalanx in type B was a modified middle one. They pointed out that in every case the loss in bony elements occurs at the apical end and proceeds a variable distance basally, and that in no case is a complete terminal present with a reduced middle phalanx. Study of the shape of the proximal phalanges shows that occasionally even some of the proximal phalanges tend to take on the hour-glass shape (Battle et al., 1973).

In conclusion, it is very likely that brachydactyly $B$ is an apical dystrophy in which the terminal bones are the middle phalanges.

\section{FARRABEE TYPE. BELL TYPE A-1}

\section{Description}

The hands (Fig. 3) are usually broad with proportionate shortening of all the digits. The distal interphalangeal creases are usually missing. Forty-four $x$-rays of type A-1 were examined (Hasselwander, 1903; Drinkwater, 1907, 1912, 1914; Marshall, 1929; Nissen, 1933; Itlis, 1944; Komai, 1953; Haws and McKusick, 1963; Hoefnagel and Gerald, 1966).

All the hand bones may be reduced in size (Hoefnagel and Gerald, 1966). The most severely shortened bones were the middle phalanges which may be fused with the distal phalanges (Fig. 3C). If the middle phalanges were present, the same pattern was observed as in the normal hand, that is, the longest phalanx was the third, the next longest the

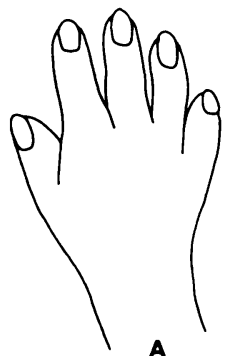

A

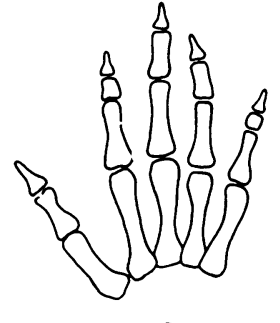

B fourth, then the second, and the fifth was the smallest (Fig. 3B). If only one finger had a fused middle and distal phalanx, it was the fifth; if two fingers showed fusion, they were the second and fifth; if three fingers showed fusion, they were the fourth, second, and fifth.

The metacarpals may be shortened, but rarely the first one. The proximal phalanges were often shortened. Itlis (1944) pointed out that the shaft of the metacarpals and proximal phalanges may be thin, and the epiphyses relatively broad, giving the bone an hour-glass contour. Though this feature is not usually mentioned, it can be found in many of the patients with type A-1 brachydactyly. The proximal phalanx of the thumb was markedly shortened and may be malformed. The distal phalanges and nails were usually normal. Accessory carpal bones were noted by Nissen (1933).

Radial clinodactyly of the fourth finger is a component of type A-4 (McKusick, 1975). However, it was found in 30 of the $44 x$-rays examined. Clinodactyly was also often present in the fifth finger and ulnar clinodactyly may be present in the second and third fingers.

Epiphyses are often missing in the very short phalanges. If present, they may be malformed, or there may be accessory epiphyses (Nissen, 1933; Hoefnagel and Gerald, 1966). Premature fusion of the epiphyses may occur (Drinkwater, 1914), or the bone age may be delayed (Nissen, 1933; Hoefnagel and Gerald, 1966).

The feet show a similar pattern of abnormalities, with absent or rudimentary middle phalanges and proximal phalanx of the big toe.

A skeletal survey was done by Haws and McKusick (1963). The distal ends of the radius and tibia were sloping, the styloid process of the ulnar was missing, the glenoid fossa was shallow, and the head of the humerus was more elliptical than round. In the hip, the acetabulum was rather shallow, the articular surfaces were irregular, and the neck of the femur was usually short with a mushroom appearance of the femoral head. Hoefnagel and Gerald (1966) also noted an absent styloid process in one patient, and 
Nissen (1933) reported a poorly developed ulnar styloid and lower radius.

Most affected families have short stature which is the result of shortening of the long bones.

\section{Discussion}

In brachydactyly A-1 each middle phalanx may be proportionately shortened, or the second and fifth middle phalanges may be more shortened than the middle two. It seems likely that a mild expression of this gene would be normal third and fourth middle phalanges and small middle phalanges in digits 2 and 5. If this were true, then McKusick type A-4 would be one end of the spectrum of type A-1.

It is usually assumed that if a middle phalanx is very short it becomes fused with the distal one. The pattern of the most severely affected middle phalanges being in digit 5 , then 2 , then 4 , then 3 is observed again when some digits show fusion, that is, if only the middle phalanx is present it is on the third digit and so on. Whenever the middle phalanges are small or absent, no joint forms and the distal interphalangeal skin crease is missing.

Symphalangism and brachydactyly are closely related, and there is an excellent review of the subject (Herrmann, 1974). Symphalangism may be found in brachydactylies A, B, C, and E. A very short phalanx could fuse with an adjacent one, and, conversely, if two bones fuse this could produce brachydactyly. Thus, symphalangism can be both the cause and the effect of brachydactyly. The mutation brachydactyly in the mouse (Grüneberg and Lee, 1973) is an animal model of one type of brachydactyly and symphalangism.

It is possible that the proportionate dwarfism observed in the upper and lower limbs has its origin early in development, possibly in the blastema stage. In normal development the last phalanges to ossify are the middle ones. If the initial blastema were short, the middle ones may be most severely affected. Premature fusion of the epiphyses and shaft may also contribute to the shortness of a bone (Drinkwater, 1914).

In conclusion, it is suggested that this type of brachydactyly may be a more or less proportionate dwarfing of the limb bones, with the middle phalanges being the most affected because they are the last to ossify.

SHORT STATURE, SHORT METACARPALS AND DISTAL PHALANGES. FITCH TYPE 10

\section{Description and discussion}

Short metacarpals and phalanges are found in a variety of syndromes. It is difficult to analyse the published reports on brachydactyly $E$ because it is

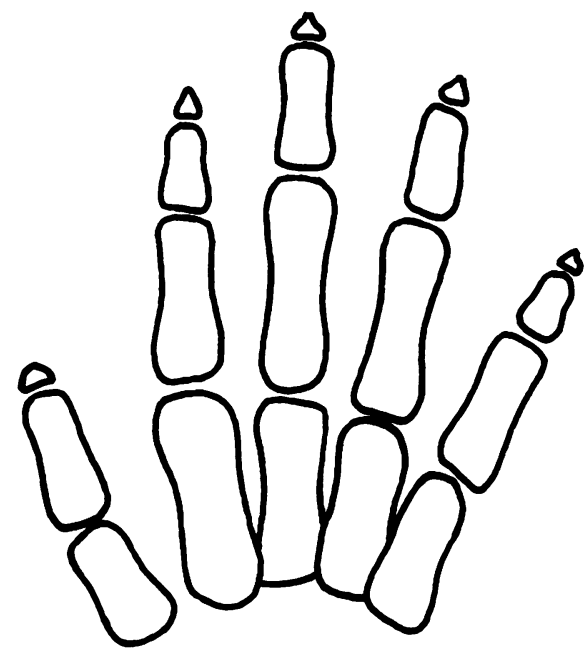

Fig. 4 Brachydactyly E. Short broad metacarpals 4 and 5 and short distal phalanges.

often not stated that an attempt has been made to rule out syndromes which can produce identical hand abnormalities, for example, pseudopseudohypoparathyroidism which has the same pattern profile (Poznanski et al., 1977).

It is proposed that the term brachydactyly $\mathrm{E}$ b used for the syndrome described by Riccardi an Holmes (1974). Affected individuals are short in stature, have normal facies, and a distinct pattern of hand malformations (Fig. 4). These consist of shor and broad fourth and fifth metacarpals and metatar sals, short middle phalanges in the fifth finger, and. short distal phalanges of the thumb. Some have shortening of other metacarpals and metatarsalsos short middle phalanges of digit 2 , and short dista phalanges of the other digits. Short stature is the result of shortening of the long bones.

In one of the pedigrees described by Riccardi and Holmes (1974), family Du, both parents wer\& normal. They had two children with brachydactyls $\mathrm{E}$ and five with stub thumb. Stub thumb was present. in a twin sister of the father. This raises the possibility that stub thumb may sometimes be the sole expression of brachydactyly $\mathrm{E}$.

In order to elucidate the pattern of abnormalities in this syndrome more families need to be described

BRACHYMESOPHALANGY 2, 3, AND 5 . BELL TYPE C

Description

Fingers 2 and 3 are usually short (Fig. 5). In the majority of cases the fourth finger is either of norm $\vec{B}$ 

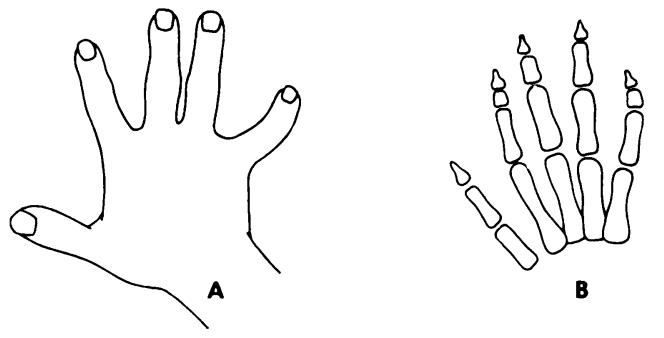

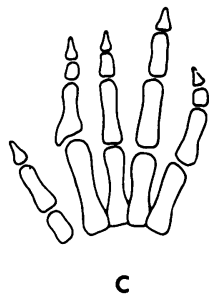

Fig. 5 Brachydactyly $C$. $B$, short middle phalanges 2, 3 , 5; $C$, abnormal proximal phalanx 2. length or less shortened than the second and third, so it is usually either the longest finger or equal in length to the third finger. Clinodactyly is often present in finger 5. Fingers 2 and 3 may show ulnar deviation. The distal finger creases may be missing in digits 2, 3, and 5 .

Examination of $85 x$-rays (Joachimstahl, 1898, 1906; Vidal, 1910; Scharff, 1912; Drinkwater, 1916; Hollander, 1918; Mohr, 1921 ; Pol, 1921; Hall, 1928; Behr, 1931; Stecher, 1936; Lossen, 1937; Becker, 1939; McNutt, 1946; Johnston and Davis, 1953; Haws, 1963; Bucke, 1964; Christiaens et al., 1965; Robinson et al., 1968; Cloherty, 1969; Temtamy and McKusick, 1969; Gnamey et al., 1971; Coberand et al., 1974; Rimoin et al., 1974; Rebollar, 1975; Fitch et al., 1979) revealed the following pattern.

The most characteristic defect is a shortening of the second, third, and fifth middle phalanges (Fig. 5B). The fourth middle phalanx is either normal in length or the least shortened. Some $x$-rays seemed to show only middle phalanges 2 and 5 to be shortened, and it is easy to confuse these with a mild expression of brachydacytly A-1. However, brachydactyly $\mathrm{C}$ and A-1 can almost always be distinguished in the following way. In brachydactyly $\mathrm{C}$ the fourth middle phalanx is longer than the third middle phalanx, whereas in brachydactyly A-1 the third middle phalanx is usually longer than the fourth. In addition, there is often a shortened first metacarpal in brachydactyly $\mathbf{C}$, whereas in brachydactyly A-1 the thumb often has a short proximal bone (Herrmann, 1974).

The metacarpals, proximal phalanges, and distal phalanges may also be affected. There may be two bones in the position of the proximal phalanges, or there may be one with evidence of fusion of two bones. The more proximal bone is often irregularly shaped and projects on the radial side of the metacarpal, so that the adult proximal phalanges 2 and/or 3 have a radial projection at the base, with ulnar deviation of the finger (Fig. 5C). In some cases the 'extra' bone is probably a large epiphysis. The metacarpals may be short, the middle phalanges may show evidence of two ossification centres (Temtamy and McKusick, 1959), and the distal phalanges may be poorly developed.

The phalangeal epiphyses may be abnormally small or large, double or absent. Ossification of the wrist bones and some of the phalanges is often retarded during childhood (Haws, 1963; Cloherty, 1969; Temtamy and McKusick, 1969; Fitch et al., 1979), but attains the adult stage during adolescence (Haws, 1963).

Hip disease was present in three members of the family described by Robinson et al. (1968). One had osteochondritis of the left hip at the age of 3. The propositus had flattening and irregularity in the density of the capital femoral epiphysis, bilaterally. The sister of the propositus had the same abnormalities. One individual in the family described by Fitch et al. (1979) had dysplasia epiphysealis capitis femoris (Meyer, 1964), which is a delayed development of the femoral epiphyses.

Other abnormalities reported are short and abnormally shaped ulnae (Cloherty, 1969; Steinbach and Brown, 1969), subluxation of the joints between the ulnae and humeri, displacement of the ulnae at their distal ends, subluxation and dislocation of the head of the radius (Steinbach and Brown, 1969; Fitch et al., 1979), radial hypoplasia and irregularity (Temtamy and McKusick, 1969; Fitch et al., 1979) Madelung's deformity (Steinbach and Brown, 1969), genu vulgarum (Robinson et al., 1968; Gnamey et al., 1971), tibia vara (Temtamy and McKusick, 1969), bilateral calcaneal and hammer toe deformities, and exostoses (Steinbach and Brown, 1969).

There may be macrophalangy, symphalangy, arachnodactyly, camptodactyly, talipes valgus (Ha ws, 1963), talipes varus (Vidal, 1910; Christiaens et al., 1965), radial or ulnar deviation of digits (Becker, 1939), hallux valgus (Temtamy and McKusick, 1969), polydactyly (Stecher, 1936; Robinson et al., 1968), limited flexion at the distal interphalangeal joints (Rimoin et al., 1974), and pronated flat feet (Cloherty, 1969).

Steinbach and Brown (1969) described a brother and sister with epiphyseal dysostosis. In both, the contour of the end plates of multiple thoracic 
vertebrae were irregular and interpediculate distances of the lumbar vertebrae were diminished. The brother had anterior wedging of the eleventh and twelfth thoracic vertebral bodies. The sister had fusion of the second and third cervical vertebral bodies.

Coberand et al. (1974) described a father and child with frontal bossing and micrognathia. The child had congenital leukaemia, short arms, and an antimongoloid slant. A 32-year-old man who died of leukaemia was reported by Unterrichter (1934).

Both normal stature (Becker, 1939; Cloherty, 1969; Fitch et al., 1979) and short stature (Vidal, 1910; Becker, 1939; Auffray and Marechal, 1971; Gnamey et al., 1971; Fitch et al., 1979) have been reported.

\section{Discussion}

In brachydactyly $\mathrm{C}$, the proximal phalanges may be normal and only the middle phalanges affected. The fourth middle phalanx is normal in length or the least severely shortened. Using these criteria, 3 pedigrees which have been classified as type A-1 should be reclassified as type $C$. These are the pedigrees of Behr (1931), Mohr (1921), and Poznanski (1974). The family of Behr (1931) had a short first metacarpal, and in Mohr's family (1921) the fourth finger of the father was slightly longer than the third. It is interesting to note that Herrmann (1974) independently designated the brachydactylies of these two families as type $C$.

The third pedigree is the one used to illustrate brachydactyly A-1 (Poznanski, 1974). The infant's fourth finger was the only one with a middle phalanx, and the adults had a fourth middle phalanx slightly longer then the third, so this was probably a brachydactyly $\mathbf{C}$ also. The second family described by Jeanselme et al. (1923) may also be brachydactyly C.

This pattern of hand malformations can be observed in other syndromes, for example, epiphyseal dysostosis (Rennell and Steinbach, 1970) and diastrophic dwarfism. It is interesting to note that Milaire (1977) predicted that a malformation might occur in which the fourth finger was the most normal. Early in fetal life there is postaxial predominance of both the apical ectodermal ridge and the mesenchymal maintenance factor. MacCabe and Parker's experiments in the chicken (1976a) and hamster limb (1976b) suggest that a gradient of a morphogenetic substance exists which is high along the postaxial border and decreases towards the preaxial border. The properties of this activity are similar to the apical ectoderm maintenance factor.

Multiple epiphyseal disturbances, including retarded epiphyseal growth and hip dysplasia, are characteristic of many chondro-osseous dystrophies. Short stature is often a component of these syndromes, and it is sometimes part of the syndron associated with brachydactyly $\mathrm{C}$.

In conclusion, it is postulated that brachydacty $\mathrm{C}$ is a type of chondro-osseous dystrophy which sometimes results in short stature.

The author is indebted to Mrs Judy Ackerman for obtaining more than 250 interlibrary loans.

\section{References}

Auffray, Y., and Marechal, J. (1971). Une observation caractéristique de brachydactylie type héréditaire II Drinkwater. Lyon Médical, 225, 1003-1004.

Bagg, H. (1929). Hereditary abnormalities of the lim. American Journal of Anatomy, 43, 167-219.

Bass, H. (1968). Familial absence of middle phalanges wi. nail dysplasia: a new syndrome. Pediatrics, 42, 318-323-

Battle, H., Walker, N., and Thompson, M. (1973). M耻 Kinder's hereditary brachydactyly. Annals of Humen Genetics, 36, 415-424.

Bean, A. (1929). A morphological analysis of the foot abnormalities occurring in the descendants of $\mathrm{X}$-rayed micke. American Journal of Anatomy, 43, 221-246.

Becker, P. (1939). Unterschiedliche phänotypische auspeàgung der anlage zur brachymesophalangie in einer sip Zeitschrift für Menschliche Vererbungs und KonstitutionsLehre, 23, 235-248.

Behr, F. (1931). Uber familiare kurzfingrigkeit, brachnt dacktylie, klinodaktylie. Fortschritte auf dem Gebiete der Rontgenstrahlen, XLIV, 516-518

Bell, J. (1951). On brachydactyly and symphalangis Treasury of Human Inheritance, 5, 1-30.

Boorstein, S. (1926). Symmetrical congenital brachydactyl( Surgery, Gynecology and Obstetrics, 43, 654-658.

Bucke, B. (1964). Ein Beitrag zumfamiliären Auftreten \&r Brachydaktylie. Zeitschrift für Menschliche Vererbungs und Konstitutions-Lehre, 37, 305-313.

Carter, T. (1959). Embryology of the Little and Bagg X-rayêd mouse stock. Journal of Genetics, 56, 401-435.

Christiaens, L., Deminatti, M., Walbaum, R., and Debeugiuy, P. (1965). A propos d'une famille atteinte de brackdactylie héréditaire type Vidal. Lyon Médical, 10, 686-69.

Clarke, D. (1915). Congenital hereditary absence of some.8f the distal phalanges. British Medical Journal, 2, 255-25区

Cloherty, J. (1969). Brachydactyly type C of Bell. Bith Defects-Original Article Series, 5, No. 3, 78-80. Thi. National Foundation-March of Dimes, New York.

Coberand, J., Rochiccioli, P., Pris, J., and Regnier, C. (1974). Association d'une brachydactylie héréditare type C $\mathrm{C} t$ d'une leucose aigue lymphoblastique. Annales de Pédiatris, 21, 885-890.

Cragg, E., and Drinkwater, H. (1917). Hereditary absence phalanges through five generations. Journal of Genetics, 81-89.

Cuevas-Sosa, A., and Garcia-Segur, F. (1971). Brachydact 89 with absence of middle phalanges and hypoplastic nants. Journal of Bone and Joint Surgery, 53-B, 101-105.

Drinkwater, H. (1907). An account of a brachydactyl迎s family. Proceedings of the Royal Society of Edinburgh, 28, 35-57.

Drinkwater, H. (1912). Account of a family showing mingor brachydactyly. Journal of Genetics, 2, 21-40.

Drinkwater, H. (1914). A second brachydactylous famil Journal of Genetics, 4, 323-340.

Drinkwater, H. (1916). Hereditary abnormal segmentati of the index and middle fingers. Journal of Anatomy Physiology, 50, 117-186. 
Fitch, N., Jequier, S., and Costom, B. (1979). Short stature, hip dysplasia and brachydactyly C. American Journal of Medical Genetics. (In the press.)

Gnamey, D., Walbaum, R., Saint-Aubert, P., and Fontaine, G. (1971). Brachydactylie héréditaire de type C. Annales de Pédiatrie, 18, 438-449.

Goswami, H., and Chaurasia, B. (1974). Gene interaction in brachydactyly. Japanese Journal of Human Genetics, 18, $405-410$.

Greene, H., and Saxton, J. (1939). Hereditary brachydactylia and allied abnormalities in the rabbit. Journal of Experimental Medicine, 69, 301-314.

Grüneberg, H. (1963). The Pathology of Development. Blackwell, Oxford.

Grüneberg, H., and Lee, A. (1973). The anatomy and development of brachypodism in the mouse. Journal of Embryology and Experimental Morphology, 30, 119-141.

Hall, G. (1928). Hereditary brachydactylism and interphalangeal ankylosis. Annals of Eugenics, 3, 265-268.

Hasselwander, A. (1903). Ueber 3 falle von brachy- und hypophalangie an hand und fuss. Zeitschrift für Morphologie und Anthropologie, 6, 511-526.

Haws, D. (1963). Inherited brachydactyly and hypoplasia of the bones of the extremities. Annals of Human Genetics, 26, 201-212.

Haws, D., and McKusick, V. (1963). Farabee's brachydactylous kindred revisited. Bulletin of the Johns Hopkins Hospital, 113, 20-30.

Herrmann, J. (1974). Symphalangism and brachydactyly syndromes. Birth Defects-Original Article Series, 10, No. 5, 23-53. The National Foundation-March of Dimes, New York.

Hertzog, K. (1968). Brachydactyly and pseudopseudohypoparathyroidism. Acta Geneticae Medicae et Gemellologiae, $17,428-437$.

Hoefnagel, D., and Gerald, P. (1966). Hereditary brachydactyly. Annals of Human Genetics, 29, 377-382.

Hollander, E. (1918). Familiare fingermissbildung. Berliner Klinische Wochenschrift, 55, 472-474.

Holmes, L., and Remensnyder, J. (1972). Hypoplasia of the second metacarpal in mother and daughter. Journal of Pediatrics, 81, 1165-1167.

Inman, O. (1941). Embryology of hereditary brachydactyly in the rabbit. Anatomical Record, 79, 483-505.

Itlis, H. (1944). A new case of typical brachydactyly. Journal of Heredity, 35, 145-148.

Jeanselme, Blamoutier, and Joannon (1923). Brachydactylie symetrique familiale. Revue Anthropologique, 33, 1-23.

Joachimstahl, G. (1898). Ueber brachydactylie und hyperphalangie. Virchows Archiv für Pathologische Anatomie und Physiologie, 151, 429-438.

Joachimstahl, G. (1906). Weitere mitteilungen uber hyperphalangie. Zeitschrift für Orthopadishe Chirurgie, 17, 462-472.

Johnston, O., and Davis, R. (1953). On the inheritance of hand and foot anomalies in six families. American Journal of Human Genetics, 5, 356-370.

Kidd, W. (1909). Abnormal phalanges in a human hand. Journal of Anatomy and Physiology, XLIV, 64-66.

Kino, Y. (1975). Clinical and experimental studies of the congenital constriction band syndrome with an emphasis on its etiology. Journal of Bone and Joint Surgery, 57-A, 636-643.

Komai, T. (1953). Three Japanese pedigrees of typical brachydactyly. Journal of Heredity, 44, 79-85.

Lossen, H. (1937). Hyperphalangie der mittelfinger bei beidseitiger partieller brachydaktylie. Fortschritte auf dem Gebiete der Rontgenstrahlen, 56, 428-438.
MacArthur, J., and McCullough, E. (1932). Apical dystrophy. Human Biology, 4, 179-207.

MacCabe, J., and Parker, B. (1976a). Evidence for a gradient of a morphogenetic substance in the developing limb. Developmental Biology, 54, 297-303.

MacCabe, J., and Parker, B. (1976b). Polarizing activity in the developing limb of the Syrian hamster. Journal of Experimental Zoology, 195, 311-317.

McKusick, V. (1975). Mendelian Inheritance in Man. Johns Hopkins University Press, Baltimore.

McNutt, C. (1946). Variability in the expression of the gene for brachydactyly in man. Journal of Heredity, 37, 359-364.

Malloch, J. (1957). Brachydactyly and symbrachydactyly. Annals of Human Genetics, 22, 36-37.

Marshall, R. (1929). Note on a family with brachydactyly. Archives of Disease in Childhood, 4, 385-388.

Meyer, J. (1964). Dysplasia epiphysealis capitis femoris. Acta Orthopaedica Scandinavica, 34, 183-197.

Milaire, J. (1977). Some disorders exhibiting brachytelephalangy. Morphogenesis and malformation of the limb. Discussion following Gorlin. Birth Defects-Original Article Series, 13, 243-257. The National FoundationMarch of Dimes, New York.

Mohr, O. (1921). A case of hereditary brachyphalangy utilized as evidence in forensic medicine. Hereditas, 2, 290-298.

Nissen, K. (1933). A study in inherited brachydactyly. Annals of Eugenics, 5, 281-301.

O'Rahilly, T., and Gardner, E. (1975). The timing and sequence of events in the development of the limbs in the human embryo. Anatomy and Embryology, 148, 1-23.

Pol (1921). Brachydaktylie, klinodaktylie, hyperphalangie und ihre grundlagen. Virchows Archiv für Klinische Medizin, 229, 388-530.

Poznanski, A. (1974). The Hand in Radiologic Diagnosis. Saunders, Philadelphia.

Poznanski, A., Werder, E., and Giedion, A. (1977). The pattern of shortening of the bones of the hand in PHP and PPHP. Radiology, 123, 707-718.

Rebollar, J. (1975). Braquidactilia hereditaria. Revista Clinica Espanola, 136, 169-172.

Rennell, C., and Steinbach, H. (1970). Epiphyseal dysostosis without dwarfism. American Journal of Roentgenology, 108, 481-487.

Riccardi, V., and Holmes, L. (1974). Brachydactyly, type E. Journal of Pediatrics, 84, 251-254.

Rimoin, D., Hollister, D., and Lachman, R. (1974). Type C brachydactyly with limited flexion of interphalangeal joints. Birth Defects-Original Article Series, 10, No. 5, 9-22. The National Foundation-March of Dimes, New York.

Robinson, G., Wood, B., Miller, J., and Baillie, J. (1968). Hereditary brachydactyly and hip disease. Journal of Pediatrics, 72, 539-543.

Scharff, A. (1912). Zwei falle von symmetrischen missbildungen der finger. Zeitschrift für Orthopadishe Chirurgie, 17, 462-472.

Stecher, W. (1936). Geneological study of a case of symmetrical congenital brachydactylia. Medical Research, 144, $5-8$.

Steggerda, M. (1942). Inheritance of short metatarsals. Journal of Heredity, 33, 233-234.

Steinbach, H., and Brown, R. (1969). Epiphyseal dysostosis. American Journal of Roentgenology, 105, 860-869.

Stiles, K. (1939). The inheritance of brachymetapody. Journal of Heredity, 30, 87-91.

Temtamy, S., and McKusick, V. (1969). Synopsis of hand malformations with particular emphasis on genetic factors. Birth Defects-Original Article Series, 5, No. 3, 125-184. The National Foundation-March of Dimes, New York. 
Unterrichter, L. (1934). Beitrage zur kenntnis der angeborenen anomallen der extremitaten. Zeitschrift für Menschliche Vererbungs und Konstitutions-Lehre, 18, 317-321.

Vidal, M. (1910). Brachydactylie symétrique et autres anomalies osseuses, héréditaires depuis plusieurs générations. Bulletin de l'Académie de Medicine, 63, 632-649.

Wells, N., and Platt, M. (1947). Hereditary phalangeal agenesis showing dominant Mendelian characteristics. Archives of Disease in Childhood, 22, 251-260.
Zavala, C., Hernandez-Ortiz, J., and Lisker, R. (19.45). Brachydactyly type $B$ and symphalangism in different members of a Mexican family. Annales de Génétique, ज18, 131-134.

Requests for reprints to Dr Naomi Fitch, Lady Dāis Institute for Medical Research, Jewish Genęral Hospital, 3755 Cote Saint Catherine Road, Montrêal, Quebec, Canada H3T 1E2. 